\title{
High prevalence of Foxp3 and IL17 in MMR-proficient colorectal carcinomas
}

\author{
S Le Gouvello, ${ }^{1,2,3}$ S Bastuji-Garin, ${ }^{2,4}$ N Aloulou, ${ }^{5}$ H Mansour, ${ }^{1}$ M-T Chaumette, ${ }^{2,6}$ \\ F Berrehar, ${ }^{1}$ A Seikour, ${ }^{6}$ A Charachon, ${ }^{2,5}$ M Karoui, ${ }^{2,7}$ K Leroy, ${ }^{2,6}$ J-P Farcet,, ${ }^{1,2}$ \\ | Sobhani ${ }^{2,5}$
}

\section{See Commentary, p 725}

- An additional table is published online only at http:// gut.bmi.com/content/vol57/ issue6

${ }^{1}$ Department of Biological Immunology, AP-HP, Hôpital Henri Mondor, Créteil, France; ${ }^{2}$ University Paris XII, Créteil,

France; ${ }^{3}$ INSERM U841, Créteil,

France; ${ }^{4}$ Department of Public

Health, AP-HP, Hôpital Henri

Mondor, Créteil, France:

${ }^{5}$ Department of

Gastroenterology, AP-HP

Hôpital Henri Mondor, Créteil,

France; ${ }^{6}$ Department of

Pathology, AP-HP, Hôpital Henri

Mondor, Créteil, France;

${ }^{7}$ Department of Surgery, AP-HP,

Hôpital Henri Mondor, Créteil,

France

Correspondence to:

Profesor I Sobhani, Department of Gastroenterology, Hôpital Henri Mondor, 51 av. du

Maréchal de Lattre de Tassigny, 94010 Créteil, France; iradj.

sobhani@hmn.aphp.fr

Revised 16 August 2007 Accepted 28 August 2007

Published Online First

19 October 2007

\section{ABSTRACT}

Background and aims: Colorectal cancer (CRC) harbours different types of DNA alterations, including microsatellite instability (MSI). Cancers with high levels of MSI (MSI-H) are considered to have a good prognosis, probably related to lymphocyte infiltration within tumours. The aim of the present study was to characterise the intratumoural expression of markers associated with the antitumour immune response in mismatch repair (MMR)proficient (MSS) colon cancers.

Methods: Ninety human colon cancers (T) and autologous normal colon mucosa (NT) were quantified for the expression of 15 markers of the immune response with quantitiative reverse transcription-PCR (qRT-PCR). mRNA expression levels were correlated with MMR status. Immunohistochemistry (IHC) was performed using both interleukin 17 (IL17) and CD3 antibodies.

Results: Expression of cytotoxic markers (FasL, granzyme $B$ and perforin), inflammatory cytokines (IL1 $\beta$, IL6, IL8, IL17 and transforming growth factor $\beta$ (TGF $\beta)$ ) and a marker of regulatory T cells (forkhead box P3 (Foxp3)) was significantly higher in tumours than in autologous normal tissues. Adjusting for MMR status, higher tumoural expression of both granzyme $B$ and perforin was associated with the MSI-H phenotype, and the perforin T/NT ratio was higher in MSI-H tissues than in MSS tissues. Higher tumoural expression of Foxp3, IL17, IL1 $\beta$, IL6 and TGF $\beta$ was associated with the MSS phenotype, and the IL17 T/NT ratio was higher in MSS tissues than in MSI-H tissues as assessed by both gRT-PCR and IHC.

Conclusions: Immune gene expression profiling in CRC displayed different patterns according to MMR status. Higher Foxp3, IL6, TGF $\beta$ and IL17 expression is a particular determinant in MMR-proficient CRC. These may be potential biomarkers for a new prognostic "test set" in sporadic CRCs.

Colorectal cancer (CRC) is the second leading cause of cancer mortality in the Western world, despite recent advances in surgery, radiotherapy and chemotherapy. ${ }^{1}$ Tumour progression of CRCs is governed by either genetic or epigenetic changes intrinsic to cancer cells, and by environmental factors. Approximately $15-20 \%$ of sporadic CRCs and nearly all large bowel malignancies in the hereditary non-polyposis colorectal cancer (HNPCC) syndrome are characterised by widespread microsatellite instability. ${ }^{2-4}$ Microsatellite instability is a genome-wide instability in repetitive DNA sequences observed at the nucleotide level, and it is caused by the inactivation or loss of expression of the mismatch repair (MMR) genes: hMSH2, hMLH1, hPMS1, hPMS2, hMSH6/GTBP or $\mathrm{MSH} 3$, as a result of either mutations or epigenetic silencing. ${ }^{5}$ Besides MMR-deficient (MSI-H) cancer, the majority of sporadic CRSs are MMR proficient (MSS) tumours, with chromosomal instability in some cases. ${ }^{67}$

Most studies revealed longer disease-free and overall survival for patients with MSI-H CRC than for patients with MSS CRC, ${ }^{8-12}$ even in the case of deep local invasion of the primary tumour. ${ }^{13}$ These studies suggested a protective role for $\mathrm{T}$ lymphocytes, which clearly infiltrated more extensively in MSI-H than in MSS CRCs. ${ }^{14}$ Pronounced lymphocytic infiltration of tumours has long been associated with an improved prognosis..$^{15} 16$ MSI in combination with a high content of intraepithelial cytotoxic lymphocytes was related to improved overall survival in a group of exclusively right-sided CRCs ${ }^{17}{ }^{18}$ suggesting that a combination of both the tumour's local lymphocytosis and MMR characterization may be useful for a more accurate prognostic assessment. Contradictory results come from mouse models of CRC, and these results are consistent with the association between either chronic inflammation ${ }^{19} 20$ or an increased number of inflammatory cells in tumours ${ }^{21}$ and tumour progression.

To determine the putative impact of microsatellite status on the antitumoural immune response, we analysed histological and molecular features of tumours in patients with sporadic CRCs. We also developed a quantitative PCR assay for 15 inflammatory and $\mathrm{T}$ lymphocyte markers in tumours with reference to the MMR status.

\section{PATIENTS AND METHODS}

\section{Study population}

This retrospective analysis included a group of 45 patients from a consecutive cohort survey study in Henri Mondor Hospital. To be eligible, patients had to have undergone surgery of primary rectal or colon tumours, for which both frozen and paraffinembedded tumoural and normal tissues were available in the tissue collection bank. None had known hereditary cancer, ulcerative colitis or Crohn's disease. Consecutive patients were routinely informed about biological research on tissues that did not include hereditary genetic characterisation. Their tissue materials could be used for the current study except if "formal opposition" was mentioned to doctors. The ethical committee approved the procedure. 


\section{Histology and pathology}

Tissues were immediately examined after surgery, and normal and tumoural representative samples were frozen, fixed in formalin, and archived in a tissue collection bank. Diagnoses and tumour descriptions were done on H\&E-stained tissues according to the pTNM classification. Histopathology was further examined for lymphocyte infiltration and for a mucous component.

\section{Analysis of MMR status by immunohistochemistry}

Representative samples from adenocarcinoma and normal mucosa adjacent to the tumour were selected in each case and paraffin sections were sent to an automated immunostainer. Tissue sections were incubated in citrate buffer with the following antibodies: G168-728 antibody (recognises hMLH1 antigen; the antibody was diluted 1:40; Pharmingen, San Diego California, USA), FE11 antibody (recognises hMSH2 antigen; the antibody was diluted 1:25; Calbiochem, Cambridge, Massachusetts, USA), 44 antibody (recognises hMSH6; the antibody was diluted 1:100; Zymed Laboratories Inc., South San Francisco, California, USA), all in a boiling water bath. An avidin-biotin complex (ABC Vectastain Kit, Vector Laboratories, Burligame, California, USA) was used to reveal the antigen. Positive controls included slides from tumours with normal expression of hMLH1, hMSH2 and hMSH6; negative controls included slides with no primary antibodies. Two observers with no prior knowledge of the PCR results assessed all cases independently, and cases with discrepancies were further evaluated until agreement was reached between the observers.

\section{Analysis of IL17 expression by immunohistochemistry}

Representative samples $(n>5)$ from tumoural and autologous normal mucosa were selected for each case, and paraffinembedded sections $(4 \mu \mathrm{m})$ were treated by boiling in citrate buffer $(\mathrm{pH} 6)$ in a microwave $(800 \mathrm{~W}, 5 \mathrm{~min} \times 3)$. Endogenous peroxidase activity was blocked by incubation in $3 \%$ hydrogen peroxide for $20 \mathrm{~min}$ followed by a wash in phosphate-buffered saline (PBS) for $5 \mathrm{~min}$. Non-specific antibody-binding sites were coated by the addition of a horse serum (1:20 in PBS, for $25 \mathrm{~min})$. Serum was then removed and antihuman IL17 goat antibody (R\&D Systems, Lille, France) diluted in the PBS (1:40) was added to the tissue sections (room temperature for $1 \mathrm{~h}$ ). Immunohistochemical staining was undertaken using a Vectastain Universal Elite kit according to the manufacturer's instructions (Vector Laboratories). The chromagen, Sigmafast $\mathrm{DAB} \quad\left(3^{\prime}, 3^{\prime}\right.$-diaminobenzidine) (Sigma-Aldrich, St Louis, Missouri, USA), was incubated with the tissue sections in the dark (room temperature for $4 \mathrm{~min}$ ). The sections were then counterstained with haematoxylin.

For double staining IL17/CD3, the goat antihuman IL17 antibody (diluted 1:40) was applied first and incubated for $2 \mathrm{~h}$. Immunohistochemical staining was undertaken using a Vectastain AP kit according to the manufacturer's instructions (Vector Laboratories) and visualization was done with Naphthol/Fast Red (Sigma-Aldrich). Subsequently, a rabbit antihuman CD3 (diluted 1:50 in PBS; Dako, France) was incubated for $1 \mathrm{~h}$. Immunohistochemical staining was undertaken using the ImmPRESS system (Vector Laboratories) and visualization was done with DAB substrate.

\section{Analysis of microsatellite stability by PCR}

Formalin-fixed paraffin-embedded (FFPE) sections from tumours were stained with $\mathrm{H} \& \mathrm{E}$, and were macrodissected if necessary to select a tissue fragment comprising $>40 \%$ tumour cells. Normal and tumour autologous DNA was extracted from a $50 \mu \mathrm{m}$ FFPE or frozen tissue section with QiAmp DNA mini kits (Qiagen, Courtaboeuf, France), according to the manufacturer's instructions. The genetic instability (MSI-H) status of the tumours was established using pentaplex PCR for markers as described by Suraweera et al. ${ }^{22}$ Microsatellites were coamplified in a single $20 \mu \mathrm{l}$ pentaplex fluorescent PCR, containing $0.1 \mu \mathrm{M}$ Bat-25, $0.25 \mu \mathrm{M}$ Bat-26 and NR-22, $0.5 \mu \mathrm{M}$ NR-24 and NR-21 primers, $0.15 \mathrm{mM}$ dNTP, $1.5 \mathrm{mM} \mathrm{MgCl}_{2}, 1 \times$ GeneAmp PCR Buffer II (Applied Biosystems, Courtaboeuf, France), $50 \mathrm{ng}$ of genomic DNA and $0.5 \mathrm{U}$ of AmpliTaq Gold DNA polymerase (Applied Biosystems). The PCR program was denaturation $\left(95^{\circ} \mathrm{C}, 10 \mathrm{~min}\right)$, then 35 amplification cycles (denaturation $\left(95^{\circ} \mathrm{C}, 30 \mathrm{~s}\right)$, annealing $\left(55^{\circ} \mathrm{C}, 45 \mathrm{~s}\right)$ and extension $\left.\left(72^{\circ} \mathrm{C}, 30 \mathrm{~s}\right)\right)$, and a final elongation step $\left(72^{\circ} \mathrm{C}, 7 \mathrm{~min}\right)$. Separation and detection of the fluorescent PCR products were performed on an ABI PRISM 3100 Genetic Analyzer (Applied Biosystems), and the data were analysed with GeneScan Analysis Software (Applied Biosystems). The MSI-H phenotype was defined as the detection of length alterations of at least three markers in tumoural versus normal DNAs from the same individual. ${ }^{22}$ We found that 31/45 tumoural tissues had the MSS phenotype, and 14/45 had the MSI-H phenotype.

\section{Quantitative reverse transcription-PCR}

Total RNA was prepared from 90 colorectal tumoural or autologous non-tumoural specimens, using Trizol ${ }^{\circledR}$ reagent (Gibco-BRL, Life Technologies, Cergy-Pontoise, France) following the manufacturer's protocol. To avoid misinterpretation of the variability in marker gene expression due to heterogeneity of the cellular distribution and/or leucocyte densities in tissue samples, 10 sections of $50 \mu \mathrm{m}$ for each sample were verified before extracting total RNA. Microdissection was used if necessary to select tumour sections with tumoural cells $>60 \%$ of total. We normalised the ratio of mRNA copy number of the gene of interest/CD3 mRNA for each sample. First-strand cDNA was synthesized in reverse transcription samples, each containing: $2 \mu \mathrm{g}$ of total RNA isolated from colorectal tissue, 16 $\mathrm{U} / \mu \mathrm{l} \quad \mathrm{M}-\mathrm{MLV}$ reverse transcriptase (Gibco-BRL), $4 \mu \mathrm{M}$ oligo(dT)12-18 (Amersham-Pharmacia Biotech, Saclay, France) and $0.8 \mathrm{mM}$ mixed dNTPs (Amersham-Pharmacia Biotech). Quantitative reverse transcription-PCR (RT-PCR) was performed in a LightCycler 2.0 System (Roche Diagnostics, Meylan, France) using a SYBR Green PCR kit or a Hybridization Probes PCR Kit from Roche Diagnostics, as previously described. ${ }^{23}{ }^{24}$ The sequences of primers and probes are indicated in the Supplementary data. Normalisation was achieved by quantification of the expression of the control housekeeping gene (HKG) $\beta 2 \mu$ globulin, which was chosen as the control among three HKGs tested because of its stable expression in tumoural and non-tumoural specimens (data not shown). All PCR conditions were adjusted in order to obtain equivalent optimal amplification efficiency between the different assays. Chemokine receptor 1 (CXCR1), CD3, IL8, IL17, granzyme A (GzA), perforin, and FoxP3 mRNA expression was quantified by the relative quantification of real-time PCR according to Gibson et al, ${ }^{25}$ using the SYBR Green PCR Kit, and using peripheral blood mononuclear cells stimulated with phorbol myristate acetate and ionomycin for $1 \mathrm{~h}$ as the calibrator sample. CD3, IL1 $\beta$, tumour necrosis factor $\alpha$ (TNF $\alpha$ ), 
IL6, interferon $\gamma$ (IFN $\gamma$ ), IL4, TGF $\beta$, IL10, GzB and FasL mRNA expression was quantified by absolute quantification of realtime PCR using the Hybridization Probes PCR Kit from Roche Diagnostics. The copy number for all target genes and for the HKG was obtained by plotting sample Ct values against the standard curve obtained by analysing the corresponding "quantitative DNA standard" 26 dilution series using the LightCycler software 4.0, and the magnitude of target gene mRNA expression is calculated as the copy number of the target gene per $10^{6}$ copies of $\beta 2 \mu$ globulin. All PCR experiments were done in duplicate.

\section{Statistical analysis}

Results of the quantification of CD3, IL8, CXCR1, IL1 $\beta$, IL6, TGF $\beta$ and TNF $\alpha$ expression are presented as the median and interquartile range (IOR) of the ratio of the immune marker gene to HKG mRNA expression. IL4, IL10, IL17, Foxp3, FasL, perforin, GzA and GzB are mainly expressed in CD3 mRNAexpressing leucocytes. Therefore, for normalisation between specimens, we used the ratio of mRNA copy number of each marker gene/CD3.

Non-parametric tests were used because of the non-normal distributions of mRNA levels. Overall differences in immune marker expression between the tumoural $(T)$ and autologous non-tumoural (NT) specimens were analysed by using the paired non-parametric Wilcoxon signed-rank test. For significant variations, gene expression levels between tumoural and non-tumoural specimens were also compared in each phenotypic subgroup (MSI-H and MSS). Differences between MSI-H and MSS phenotypes were evaluated by comparing the T/NT ratio of mRNA expression using the two-sample Wilcoxon rank-sum test. All tests were two-tailed. An adjustment for multiple testing was done using the Bonferroni correction, and $p$ values $\leqslant 0.003(0.05 / 15=0.0033)$ were considered statistically significant. Data were analysed using Stata Statistical software (StataCorp 2003, Release 8.0, College Station, Texas, USA)

\section{RESULTS}

\section{Characterisation of patients with CRCs}

Patients with the MSI-H phenotype were not significantly different from those with the MSS phenotype in terms of age, diagnosis, therapy or surveillance procedures (table 1 ). The rate of tumour relapse within a 36-month follow-up was not different depending on MMR status. Tumours with the MSI$\mathrm{H}$ phenotype were right-sided with significantly different histopathological features: they had more lymphocyte infiltration and a greater mucoid component, and less local or systemic tumour cell extension.

\section{The MSI-H phenotype correlates with the presence of cytotoxic markers}

The CD3 mRNA copy number in tumoural (T) tissues was not significantly different from that in autologous (NT) tissue fragments $(0.18(0.13$ to 0.28$)$ vs $0.17(0.11$ to 0.26$))$ when all samples were considered (irrespective of MMR status). The CD3 T/NT ratio did not differ between MSI-H and MSS tissues. The expression ratios of the cytotoxic parameters, FasL/CD3, perforin/CD3 and $\mathrm{GzB} / \mathrm{CD} 3$, were significantly higher in tumour tissues than in autologous NT specimens (table 2). Adjusting on MMR status, only the perforin $\mathrm{T} / \mathrm{NT}$ ratio was higher in MSI-H tissues than in MSS tissues. The expression of $\mathrm{GzB} / \mathrm{CD} 3$ was significantly higher in tumour (as compared with NT) specimens only if they had an MSS phenotype. The GzA/ CD3 ratio did not differ between tumoural and autologous NT specimens.

\section{MSS phenotype and higher Foxp3 and IL17 expression in tumour infiltrates}

Overall analysis showed that the expression ratios IL17/CD3 and Foxp3/CD3 (table 2), and IL8, IL1 $\beta$, IL6 and TGF $\beta$ expression (table 3) were significantly higher in tumour tissues than in autologous NT specimens. However, adjusting for MMR status, the higher expression of Foxp3, IL17, IL1 $\beta$, IL6 and TGF $\beta$ was observed only in MSS phenotype tumours (tables 2 and 3). The IL17 T/NT ratio was higher in MSS tissues than in

Table 1 Characteristics of the study population

\begin{tabular}{|c|c|c|c|c|}
\hline \multirow[b]{3}{*}{ Parameters } & \multirow{2}{*}{$\begin{array}{l}\text { All cases } \\
(n=45)\end{array}$} & \multirow{2}{*}{$\begin{array}{l}\text { MSS } \\
(n=31)\end{array}$} & \multirow{2}{*}{$\frac{\text { MSI-H }}{(n=14)}$} & \multirow[b]{3}{*}{ p Value* } \\
\hline & & & & \\
\hline & n (\%) & n (\%) & n (\%) & \\
\hline Gender (F) & $21(47)$ & $11(35)$ & $10(71)$ & 0.05 \\
\hline Mean age at surgery (SD) & $69.7(1.5)$ & $68.8(1.8)$ & $71.8(2.8)$ & 0.40 \\
\hline Right-sided tumour & $19(42)$ & $9(29)$ & $10(71)$ & 0.01 \\
\hline No or poor differentiation & $27(60)$ & $20(70)$ & $7(50)$ & 0.21 \\
\hline Mucous component & $4(1)$ & $0(0)$ & $4(40)$ & 0.01 \\
\hline Lymphocyte infiltration $†$ & $14(31)$ & $1(3)$ & $13(93)$ & 0.0001 \\
\hline \multicolumn{5}{|l|}{ Tumour staging } \\
\hline pT 1-2 & $4(9)$ & $2(6)$ & $2(14)$ & \\
\hline pT 3 & $27(60)$ & $16(52)$ & $11(79)$ & \\
\hline pT 4 & $14(31)$ & $13(42)$ & $1(7)$ & 0.05 \\
\hline No & $26(58)$ & $15(48)$ & $11(79)$ & \\
\hline $\mathrm{N} 1-2$ & $19(42)$ & $16(52)$ & $3(21)$ & 0.10 \\
\hline Synchronous metastasis & $22(49)$ & $19(61)$ & $3(21)$ & 0.02 \\
\hline Vascular emboli & $25(56)$ & $20(65)$ & $5(36)$ & 0.03 \\
\hline Perinervous infiltration & $7(16)$ & $5(16)$ & $2(14)$ & 1 \\
\hline Relapse within 36 months of follow-up & $10(22)$ & $8(26)$ & $2(14)$ & $0.47 \%$ \\
\hline
\end{tabular}

${ }^{*} p$ Value of Fisher exact test or Mann-Whitney test as appropriate. $\dagger$ Assessed by histopathology evaluation (yes $=+$ to ++ ;

no $=0$ to $+(-)$. \$p Value of log-rank test for equality of survivor functions.

$\mathrm{F}$, female, MSS, microsatellite stability; MSI-H, high-frequency microsatellite instability. 
Table 2 Gene expression levels/CD3 in colon cancers compared with normal mucosa

\begin{tabular}{|c|c|c|c|c|c|}
\hline \multirow{2}{*}{$\begin{array}{l}\text { Target gene } \\
\text { expression }\end{array}$} & \multirow[b]{2}{*}{$\mathbf{n}$} & \multicolumn{2}{|l|}{ Tissues } & \multirow[b]{2}{*}{ p Value* } & \multirow[b]{2}{*}{ T/NT ratio } \\
\hline & & Non-tumoural & Tumoural & & \\
\hline Fas ligand & (45) & $1390(463-2055)$ & $2294(964-3842)$ & $<0.001$ & \\
\hline MSS & (31) & 1500 (274-2040) & 1731 (708-3376) & 0.01 & 1.7 \\
\hline MSI-H & (14) & 1275 (750-2154) & $3305(2031-7821)$ & 0.02 & 2.6 \\
\hline $\mathrm{p}$ Value $\dagger$ & & & & & 0.68 \\
\hline Perforin & (45) & $13.2(8.1-17.9)$ & $19.3(13.2-41.5)$ & 0.002 & \\
\hline MSS & (31) & $13.5(8.8-20.9)$ & $17.1(11.3-35.1)$ & 0.07 & 1.2 \\
\hline MSI-H & (14) & $8.9(5.4-18.5)$ & $38.5(18.5-69.0)$ & 0.009 & 3.2 \\
\hline $\mathrm{p}$ Value $\dagger$ & & & & & 0.003 \\
\hline Granzyme A & (45) & $1.6(1.0-2.6)$ & $1.6(1.0-2.0) 1$ & 0.72 & \\
\hline MSS & (31) & $1.6(1.2-2.5)$ & $1.5(.9-2.0)$ & & \\
\hline $\begin{array}{l}\text { MSI-H } \\
\mathrm{p} \text { Value } \dagger\end{array}$ & (14) & $1.6(0.9-2.6)$ & $2.1(1.6-3.5)$ & & \\
\hline Granzyme B & (45) & 5555 (2992-11 501) & 19065 (14 440-30 586) & $<0.0001$ & \\
\hline MSS & (31) & 5545 (2586-7640) & 16289 (9396-23 507) & $<0.0001$ & 3.4 \\
\hline MSI-H & (14) & 7915 (4167-14 431) & 24758 (17 223-61 150) & 0.006 & 4.1 \\
\hline $\mathrm{p}$ Value $\dagger$ & & & & & 0.71 \\
\hline IL4 & (45) & 99 (48-421) & $238(120-450)$ & 0.06 & \\
\hline MSS & (31) & $81(46-421)$ & $238(120-450)$ & & \\
\hline $\begin{array}{l}\text { MSI-H } \\
\text { p Value } \dagger\end{array}$ & (14) & $124(50-515)$ & $203(91-471)$ & & \\
\hline IL10 & (45) & $227(88-529)$ & 284 (199-527) & 0.06 & \\
\hline MSS & (31) & $250(76-646)$ & $284(203-509)$ & & 1.7 \\
\hline MSI-H & (14) & $154(106-529)$ & 317 (143-654) & & 1.2 \\
\hline $\mathrm{p}$ Value $\dagger$ & & & & & 0.68 \\
\hline IL17 & (45) & $0.6(0.2-1.8)$ & $4.5(1.8-11.5)$ & $<0.0001$ & \\
\hline MSS & (31) & $0.5(0.2-1.8)$ & $7.2(2.3-18.8)$ & $<0.0001$ & 13.7 \\
\hline MSI-H & (14) & $1.4(0.6-2.0)$ & $2.4(0.4-4.4)$ & 0.30 & 1.4 \\
\hline $\mathrm{p}$ Value $\dagger$ & & & & & 0.002 \\
\hline Foxp3 & (45) & $2.7(1.7-4.0)$ & $15.6(11.2-20.1)$ & $<0.001$ & \\
\hline MSS & (31) & $2.6(1.7-3.9)$ & $16.0(13.7-21.0)$ & $<0.0001$ & 6.8 \\
\hline MSI-H & (14) & $3.1(1.7-6.2)$ & $10.5(3.9-19.7)$ & 0.07 & 3.2 \\
\hline $\mathrm{p}$ Value $\dagger$ & & & & & 0.04 \\
\hline
\end{tabular}

MSI-H tissues. Moreover, quantification by qRT-PCR of IL22 expression, another IL17-producing $\mathrm{T}$ cell- $\left(\mathrm{T}_{\mathrm{H}}-17\right.$ cell) secreted cytokine, showed IL22 overexpression in MSS tumour tissues compared with MSI-H tumour tissues $(p=0.042$ for the ratio difference between MSI T/NT and MSS T/NT). The IL10/CD3, IL4/CD3 ratios (table 2), and CXCR-1 and TNF expression (table 3) did not differ between the tumoural and autologous non-tumoural specimens. Expression of IFN $\gamma$ was not detected in any specimen.

\section{Immunohistochemistry}

IL17-immunoreactive cells were rarely detected in normal tissues in the lamina propria (fig 1A). However, their number was higher in tumour sections than in autologous normal tissues. IL17 cell infiltration was higher in MSS tumours than in MSI tumours (fig 1B). Only a few CD3+ cells in tumours were double-stained with IL17 antibody (fig 1c).

\section{DISCUSSION}

Elucidation of the nature of the intratumoural inflammatory reaction is relevant not only to understand better the pathobiology of CRCs but also to assess the possible influence of the host immune response on patient outcome. Our study examined the differences in the pattern of inflammatory and immune response markers expressed in the tumour microenvironment of a series of 45 tumours from patients with sporadic CRC. About one-third of the patients had MSI-H colorectal cancer, although no-one displayed HNPCC syndrome and/or the Bethesda criteria. ${ }^{27}$ MSI-H phenotype tumours, as assessed by immunohistochemistry, showed more pronounced lymphocytic infiltration than MSS phenotype tumours. The MSI-H phenotype was associated with a higher expression level of cytotoxic cell markers, especially perforin. Conversely, the MMR-proficient (MSS) phenotype was associated with higher expression levels of Foxp3, a marker of regulatory $\mathrm{T}$ cells, and of inflammatory (IL1 $\beta$, IL6, IL8, IL17) or suppressive (TGF $\beta$ ) cytokines, with IL17 expressed at particularly high levels. No difference was observed between MSI-H and MSS tumours regarding CD4+ Th1 and Th2 cell subset infiltration, as assessed by the mRNA levels of the relevant cytokines (IFN $\gamma, \mathrm{TNF} \alpha$ and IL4). Thus, we show for the first time a paradoxical gene expression signature combining markers associated with inhibition of the antitumour immune response (TGF $\beta$, Foxp3) and 
Table 3 Gene expression levels in MSI-H and MSS colon cancers compared with normal mucosa

\begin{tabular}{|c|c|c|c|c|c|}
\hline \multirow{2}{*}{$\begin{array}{l}\text { Target gene } \\
\text { expression }\end{array}$} & \multirow[b]{2}{*}{$\mathbf{n}$} & \multicolumn{2}{|l|}{ Tissues } & \multirow[b]{2}{*}{ p Value* } & \multirow[b]{2}{*}{ T/NT ratio } \\
\hline & & Non-tumoural & Tumoural & & \\
\hline IL8 & (45) & $0.3(0.1-0.7)$ & $7.5(3.4-12.2)$ & $<0.0001$ & \\
\hline MSS & (31) & $0.2(0.1-0.7)$ & $7.5(3.4-11.0)$ & $<0.0001$ & 35.5 \\
\hline MSI-H & (14) & $0.4(0.1-0.9)$ & $9.8(3.0-16.5)$ & 0.001 & 26.0 \\
\hline $\mathrm{p}$ Value $\dagger$ & & & & & 0.79 \\
\hline CXCR1 & (45) & $0.2(0.1-0.4)$ & $0.6(0.3-1.3)$ & 0.004 & \\
\hline MSS & (31) & $0.2(0.1-0.4)$ & $0.5(0.2-0.7)$ & & \\
\hline $\begin{array}{l}\text { MSI-H } \\
\text { p Value } \dagger\end{array}$ & (14) & $0.2(0.001-0.8)$ & $0.9(0.4-2.9)$ & & \\
\hline IL1及 & (45) & $336(104-1047)$ & $2143(686-4729)$ & $<0.0001$ & \\
\hline MSS & (31) & $330(73-622)$ & 1852 (489-3392) & $<0.0001$ & 4.7 \\
\hline MSI-H & (14) & $388(172-1290)$ & $3844(686-5756)$ & 0.01 & 4.5 \\
\hline \multicolumn{2}{|l|}{$\mathrm{p}$ Value $\dagger$} & & & & 0.79 \\
\hline IL6 & (45) & 1014 (297-4837) & 12281 (5942-23 507) & 0.003 & \\
\hline MSS & (31) & 904 (247-4815) & $12824(3597-28160)$ & 0.002 & 19.6 \\
\hline MSI-H & (14) & 1764 (726-11418) & 11357 (7165-17 411) & 0.36 & 3.6 \\
\hline \multicolumn{2}{|l|}{$\mathrm{p}$ Value $\dagger$} & & & & 0.08 \\
\hline TGF $\beta$ & (45) & 1878 (975-2992) & $4488(2191-6061)$ & $<0.0001$ & \\
\hline MSS & (31) & $1755(962-3030)$ & 3941 (1953-5935) & $<0.0001$ & 2.2 \\
\hline MSI-H & (14) & 2007 (1054-2728) & $5264(2818-9656)$ & 0.004 & 2.5 \\
\hline \multicolumn{2}{|l|}{$\mathrm{p}$ Value $\dagger$} & & & & 0.71 \\
\hline TNF $\alpha$ & (45) & $133(75-269)$ & $216(153-390)$ & 0.22 & \\
\hline MSS & (31) & $104(65-234)$ & 199 (139-381) & & \\
\hline $\begin{array}{l}\text { MSI-H } \\
\text { p Value } \dagger\end{array}$ & (14) & $192(130-1359)$ & 222 (174-492) & & \\
\hline \multicolumn{6}{|c|}{$\begin{array}{l}\text { Results are expressed as median (first-third quartiles) of the ratio of the target gene to the housekeeping gene mRNA copy } \\
\text { numbers. } \\
{ }^{*} \mathrm{p} \text { Value of the paired non-parametric comparisons between tumoural and non-tumoural tissues (Wilcoxon signed-rank test). } \\
\text { tp Value of the non-parametric comparisons between MSS and MSI-H phenotypes. } \\
\text { After using the Bonferroni correction for multiple testing, } p \leqslant 0.003(0.05 / 15) \text { was considered statistically significant and these } \\
\text { values are indicated in bold. } \\
\text { CXCR, chemokine receptor; IL, interleukin; MSS, microsatellite stability; MSI-H, high-frequency microsatellite instability; NT, non- } \\
\text { tumoural; T, tumoural; TGF, transforming growth factor; TNF, tumour necrosis factor. }\end{array}$} \\
\hline
\end{tabular}

the protumoural inflammatory response (IL17, IL6) in the microenvironment of sporadic CRCs without microsatellite instability.

Pronounced lymphocytic infiltration is linked with longer survival in human cancers, ${ }^{16}{ }^{28-31}$ and immune suppression clearly enhances the chance of cancer appearance in human and animal models. ${ }^{32}$ However, the lack of tumour immune surveillance has been associated with the context of an inflammatory cytokine milieu (IL6, IL1 $\beta$, TNF $\alpha$, IL17). ${ }^{33}{ }^{34}$ Thus, the phenotypic and functional characterization of these lymphocytic infiltrates (ie, CD8+ T cells (central and effector memory CD8+ T cells) and CD4+ T cells (CD4+ T helper cells of types 1, 2 and 17), and regulatory/suppressive CD4+CD25+high $\mathrm{T}$ cells $\left(\mathrm{T}_{\text {reg }}\right.$ cells $)$ ] have been proven to predict prognoses in melanoma, ovarian cancer and non-Hodgkin's lymphoma. ${ }^{35} 36$ Together, the data from human studies support the existence of a cancer immunosurveillance system that involves Th1-dependent cytotoxic cells and which is locally suppressed by $T_{\text {reg }}$ cells and inflammatory products.

In $\mathrm{CRC}$, the role of tumour-infiltrating inflammatory cells and lymphocytes is still controversial. An increased number of inflammatory cells in tumours may favour tumour progression. ${ }^{21}$ Increased expression of cytotoxic CD8-positive $\mathrm{T}$ cells and increased apoptosis of tumour cells were demonstrated in small series of MSI-H CRCs by using immunohistochemical methods, ${ }^{17} 3738$ by assessment of cytotoxic marker mRNA levels (such as perforin and $\mathrm{GzB})^{39}$ and by using oligonucleotide microarray analysis and/or qRT-PCR assays. ${ }^{40-42}$ Different findings support the hypothesis that MSI-H CRCs, which are roughly considered to display a good prognosis, ${ }^{43}{ }^{44}$ may lead to the production of genetically altered proteins in the tumour microenvironment. These proteins may function as tumourspecific neoantigens able to elicit potentially effective antitumour cytotoxic responses. ${ }^{17}$ Our results provide additional evidence of the close relationship between pronounced lymphocytic infiltration and the overexpression of cytotoxic markers in MSI-H tumours, indicating a better cell-mediated tumour-specific immune response in patients. Although CRCs in general are known as poor immunogenic tumours, ${ }^{45}$ those with the MSI-H phenotype should be considered as immunogenic. However, the majority of CRCs are of the MSS phenotype. Together with the low density of the CD3-positive lymphocytic infiltrate and the low perforin expression, this phenotype could reflect the poor immunogenic capacity to generate a specific cytotoxic CD8+ T cell response. Recently, immunological data-for example, the presence of markers for $\mathrm{T}_{\mathrm{H}} 1$ and cytotoxic polarisation, the memory $\mathrm{T}$ cell type, a high density and location of immune cells within the tumour samples-were found to be a better predictor of patient survival than the histopathological methods currently used to stage CRC. ${ }^{46}{ }^{47}$ The molecular phenotype of human CRC based on MMR status has not been taken into consideration in these two latter studies. Because the MSI-H phenotype is usually described in only $15-20 \%$ of sporadic CRCs, it is unlikely that all tumours (88 out of 104) presenting with a higher density of CD3+ plus CD45+ cells and with longer duration of disease-free survival in 
Figure 1 Interleukin 17 (IL17)immunoreactive cells in colonic tissues. IL17-producing cells are mainly located in the lamina propria in the normal (NI) colonic mucosa $(A$, left with higher magnification $\times 60$ in the insert at the bottom) as compared with the control (right) with the main antibody omitted during the immunohistochemistry reaction. IL17-immunostained cells infiltrated tumours with the MSS (macrosatellite-stable) phenotype ( $B$, left) in a proportion higher than in those with the MSI (macrosatelitte-instable) phenotype ( $B$, right). CD3 immunostaining in a colon tumour section ( $C$, left) as compared with a double staining reaction using CD3 and IL17 (brown and red, respectively) in the same colon cancer (C, right with magnification on optic microscopy $\times 20$ and higher magnification $\times 60$ of some double-stained cells in the insert at the bottom. Mag, magnification.
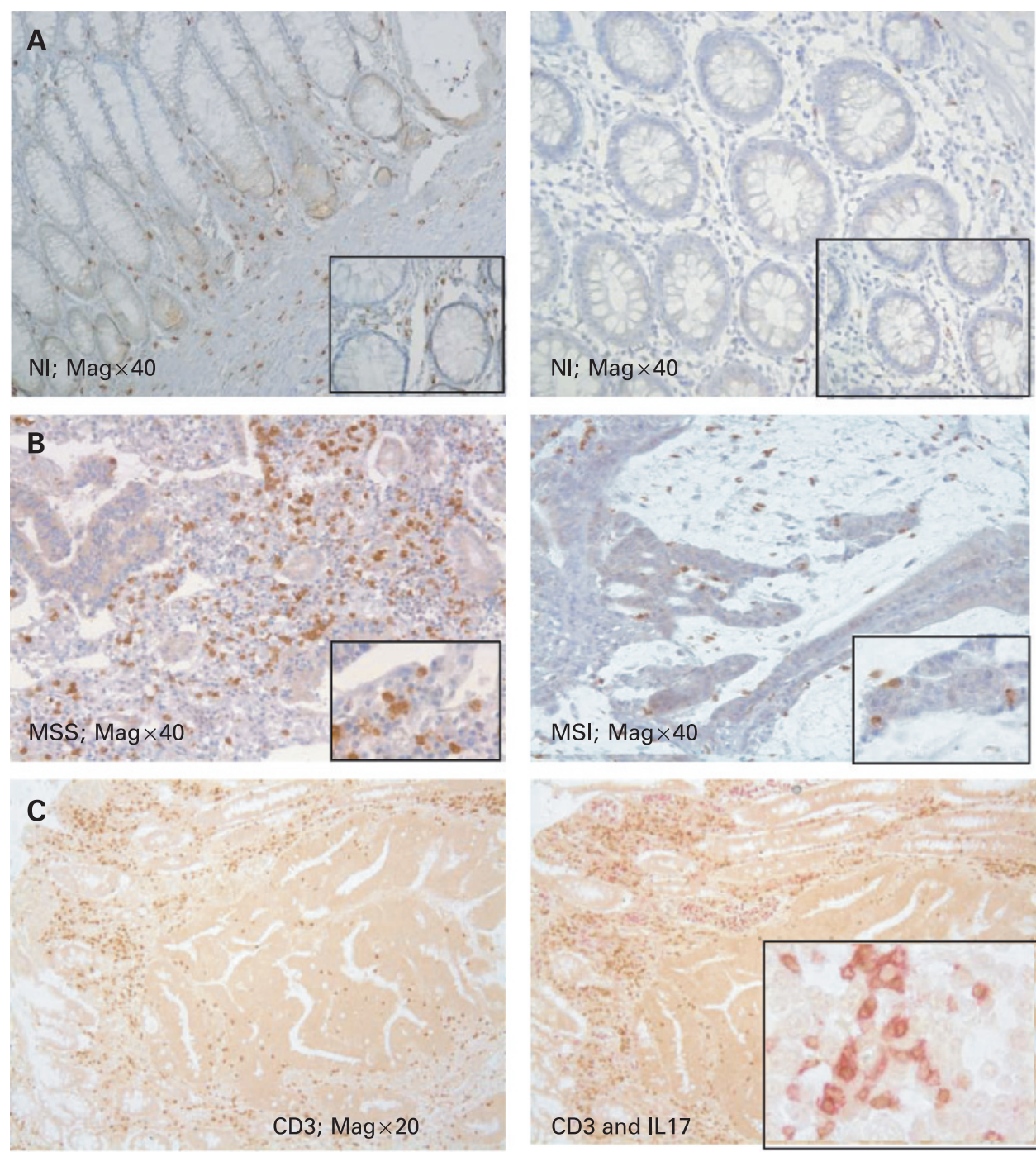

related patients, in this series, ${ }^{46}{ }^{47}$ might be of the MSI-H phenotype. Thus, MSI-H CRC may still be considered as a single prognostic marker in CRC.

We report for the first time the coexistence of higher expression of markers associated with the antitumour immune response (Foxp3 and TGF $\beta$ ) and of the two inflammatory cytokines IL6 and IL17, in MMR-proficient CRC. The higher expression of Foxp3 in the current study could be the hallmark of either naturally occurring, thymically produced $n T_{\text {reg }}$ cells or extrathymically generated $\operatorname{Tr} 1 / \mathrm{Th} 3$ cell infiltrates. The extrathymic $\mathrm{T}$ cells are distinct from thymically produced $\mathrm{nT}_{\text {reg }}$ cells, because they generally do not need contact-dependent mechanisms and may react to soluble cytokines (typically IL10 or TGF $\beta$; for a review, see Fehervari et al. ${ }^{48}$ ) Although CD25+ CD4+ T cells could be generated, in vitro, from peripheral naïve $\mathrm{CD} 4+\mathrm{T}$ cells of Foxp3 reporter mice, ${ }^{49}$ there is no evidence that these events could occur in physiological conditions and/or in tumour-induced immune responses in vivo. However, these unknowns do not undermine the pluripotential role of TGF $\beta$ in the maintenance of Foxp3 expression, regulatory function and homeostasis in peripheral CD4(+)CD25(+) regulatory $\mathrm{T}$ cells, ${ }^{50}$ and well established Foxp3-dependent suppressive abilities of extrathymically generated Tr1/Th3 cells. ${ }^{51}$ Moreover, the immunosuppressive capability of TGF $\beta$ is alternatively supported by its ability to prevent the maturation of dendritic cells (DCs) by maintaining a low expression of costimulatory molecules ${ }^{52}$ and by generating DCs that promote $T_{\text {reg-dependent tolerance } .{ }^{54} \text { Alternatively, tumour cells }}$ produce soluble factors such as IL6 that cause a specific DC subset to secrete bioactive TGF $\beta$, which in turn acts as a costimulator of the expansion of Foxp3-expressing $T_{\text {reg }}$ cells. ${ }^{55}$ Thus, in our study, the higher expression of TGF $\beta$, whatever the nature of the TGF $\beta$-secreting cells (eg, $\mathrm{T}_{\text {reg }}$ cells tumour cells or fibroblasts), could participate to the induction of suppressive mechanisms inducing tumour tolerance in the MSS tumour tissues.

Of potential interest for further functional investigation is analysis of the coexpression of cytokines-for example, IL17Aexpressing cells, in the context of IL6 and TGF $\beta$ expression in MSS tumour tissues. Although the differentiation of $\mathrm{T}_{\mathrm{H}^{-}}-17$ cells was described to be determined by exposure to TGF $\beta$ and IL6, ${ }^{56}{ }^{57}$ we cannot definitively conclude whether the changes in cytokine gene expression in MSS tumours are caused by tumour-infiltrating lymphocytes or innate immune cells, rather than by tumour-infiltrating fibroblasts. Using double staining procedures on immunocytochemistry, we could show that the minority of IL17-immunostained cells were also of the CD3 phenotype. This is consistent with data from the literature 
indicating that $<15 \%$ of CD4+ conventional T cells are IL17 $\left(\mathrm{T}_{\mathrm{H}}-17\right)$ when about $60 \%$ of the IL17A-producing cells are $\gamma \delta \mathrm{T}$ cells, and $25 \%$ are natural killer $\mathrm{T}$-like cells. $\mathrm{T}_{\mathrm{H}}-17$ cells coexpress IL17 and IL22. ${ }^{58}$ In an attempt to discriminate further between the three types of IL17-secreting T cells, we quantified IL22 expression in the same set of MSS and MSI-H tissue samples and autologous controls, and found higher IL22 expression levels in MSS tumours than in MSI-H tumour tissues. Although indirect, this result supports the hypothesis of a higher infiltration of MSS tumours by $\mathrm{T}_{\mathrm{H}^{-}}-17$ cells, potentially linked to the simultaneous higher expression of TGF $\beta$ and IL6 in the microenvironment of MSS tumours. Our results are in agreement with those of different studies showing that the enhanced tumour growth elicited by IL17 was associated both with its proangiogenic effect ${ }^{59}$ and with the increased expression of IL6 at the tumour site. ${ }^{60}$ Our data are also consistent with a previous report conducted in a murine tumour model. It showed that IL17 may exert protumour or antitumour effects, depending on the immunogenicity of the tumour and the presence of specific cytolytic T lymphocytes. ${ }^{61}$ Although further investigations are needed to clarify the cellular sources of TGF $\beta$, IL6 and IL17 ${ }^{35}{ }^{2}$ we think it is worth considering that the poorly immunogenic MSS tumour might generate regulatory $\mathrm{T}$ cells instead of antitumour effector cytotoxic cells, leading to exacerbation, and not to control, of the disease. We would suggest that the coexistence of higher Foxp3, IL6, TGF $\beta$ and IL17 expression represents a potential biomarker for the future development of a new prognostic "test set" for sporadic colon cancer.

Acknowledgements: We would like to thank Professor Philipe Gaulard, Mrs Nadine Martin Garcia, and Mr and Mrs Feriel Bouabbas for their management and technical assistance. We also thank the "Ligue Nationale Contre le Cancer LNCC" and ACD (Association Charles Debray) for their financial support.

Funding: Supported by grants from DRCD Assistance Publique-Hôpitaux de Paris, Ligue Contre le Cancer, ACD.

Competing interests: None.

Ethics approval: The ethical committee approved the procedure.

Patient consent: Patients were routinely informed about biological research on tissues that did not include hereditary genetic characterisation and their tissue materials was used for the current study except if "formal opposition" was mentioned to doctors.

\section{REFERENCES}

1. Boyle P, Leon ME. Epidemiology of colorectal cancer. Br Med Bull 2002;64:1-25.

2. Liu B, Nicolaides NC, Markowitz S, et al. Mismatch repair gene defects in sporadic colorectal cancers with microsatellite instability. Nat Genet 1995:9:48-55.

3. Herman JG, Umar A, Polyak K, et al. Incidence and functional consequences of hMLH1 promoter hypermethylation in colorectal carcinoma. Proc Natl Acad Sci USA 1998;95:6870-5

4. Bocker T, Ruschoff J, Fishel R. Molecular diagnostics of cancer predisposition: hereditary non-polyposis colorectal carcinoma and mismatch repair defects. Biochim Biophys Acta 1999;1423:01-010.

5. Jascur T, Boland CR. Structure and function of the components of the human DNA mismatch repair system. Int J Cancer 2006;119:2030-5.

6. Georgiades IB, Curtis LJ, Morris RM, et al. Heterogeneity studies identify a subset of sporadic colorectal cancers without evidence for chromosomal or microsatellite instability. Oncogene 1999:18:7933-40.

7. Tang R, Changchien CR, Wu MC, et al. Colorectal cancer without high microsatellite instability and chromosomal instability - an alternative genetic pathway to human colorectal cancer. Carcinogenesis 2004;25:841-6.

8. Lothe RA, Peltomaki P, Meling Gl, et al. Genomic instability in colorectal cancer: relationship to clinicopathological variables and family history. Cancer Res 1993;53:5849-52.

9. Watson $\mathbf{P}$, Lin KM, Rodriguez-Bigas MA, et al. Colorectal carcinoma survival among hereditary nonpolyposis colorectal carcinoma family members. Cancer 1998;83:259-66.

10. Wright CM, Dent OF, Barker M, et al. Prognostic significance of extensive microsatellite instability in sporadic clinicopathological stage $\mathrm{C}$ colorectal cancer Br J Surg 2000;87:1197-202.
11. Gryfe $\mathbf{R}, \mathrm{Kim} \mathrm{H}$, Hsieh ET, et al. Tumor microsatellite instability and clinical outcome in young patients with colorectal cancer. N Engl J Med 2000;342:69-77.

12. Samowitz WS, Curtin K, Ma KN, et al. Microsatellite instability in sporadic colon cancer is associated with an improved prognosis at the population level. Cancer Epidemiol Biomarkers Prev 2001;10:917-23.

13. Buckowitz A, Knaebel HP, Benner A, et al. Microsatellite instability in colorectal cancer is associated with local lymphocyte infiltration and low frequency of distant metastases. Br J Cancer 2005;92:1746-53.

14. House AK, Watt AG. Survival and the immune response in patients with carcinoma of the colorectum. Gut 1979:20:868-74.

15. Watt AG, House AK. Colonic carcinoma: a quantitative assessment of lymphocyte infiltration at the periphery of colonic tumors related to prognosis. Cancer 1978;41:279-82.

16. Jass JR. Lymphocytic infiltration and survival in rectal cancer. J Clin Pathol 1986;39:585-9.

17. Dolcetti R, Viel A, Doglioni C, et al. High prevalence of activated intraepithelial cytotoxic T lymphocytes and increased neoplastic cell apoptosis in colorectal carcinomas with microsatellite instability. Am J Pathol 1999:154:1805-13.

18. Guidoboni M, Gafa R, Viel A, et al. Microsatellite instability and high content of activated cytotoxic lymphocytes identify colon cancer patients with a favorable prognosis. Am J Pathol 2001;159:297-304.

19. Coussens LM, Werb Z. Inflammation and cancer. Nature 2002;420:860-7.

20. Clevers H. At the crossroads of inflammation and cancer. Cell 2004:118:671-4.

21. Balkwill F, Coussens LM. Cancer: an inflammatory link. Nature 2004;431:405-6.

22. Suraweera $\mathbf{N}$, Duval A, Reperant $\mathbf{M}$, et al. Evaluation of tumor microsatellite instability using five quasimonomorphic mononucleotide repeats and pentaplex PCR. Gastroenterology 2002;123:1804-11.

23. Mesel-Lemoine M, Cherai M, Le Gouvello $S$, et al. Initial depletion of regulatory $T$ cells: the missing solution to preserve the immune functions of $\mathrm{T}$ lymphocytes designed for cell therapy. Blood 2006;107:381-8.

24. Desvaux D, Schwarzinger M, Pastural M, et al. Molecular diagnosis of renal-allograft rejection: correlation with histopathologic evaluation and antirejection-therapy resistance. Transplantation 2004;78:647-53.

25. Gibson UE, Heid CA, Williams PM. A novel method for real time quantitative RT-PCR Genome Res 1996;6:995-1001.

26. Sarkar G, Bolander ME. The "looped oligo" method for generating reference molecules for quantitative PCR. Biotechniques 1994:17:864-6.

27. Umar A, Boland CR, Terdiman JP, et al. Revised Bethesda Guidelines for hereditary nonpolyposis colorectal cancer (Lynch syndrome) and microsatellite instability. J Natl Cancer Inst 2004;96:261-8.

28. Clemente CG, Mihm MC Jr, Bufalino R, et al. Prognostic value of tumor infiltrating lymphocytes in the vertical growth phase of primary cutaneous melanoma. Cancer 1996; 77:1303-10

29. Naito Y, Saito K, Shiiba K, et al. CD8+ T cells infiltrated within cancer cell nests as a prognostic factor in human colorectal cancer. Cancer Res 1998:58:3491-4.

30. Schumacher K, Haensch W, Roefzaad C, et al. Prognostic significance of activated CD8(+) T cell infiltrations within esophageal carcinomas. Cancer Res 2001;61:3932-6.

31. Nakano 0, Sato M, Naito $Y$, et al. Proliferative activity of intratumoral CD8(+) Tlymphocytes as a prognostic factor in human renal cell carcinoma: clinicopathologic demonstration of antitumor immunity. Cancer Res 2001:61:5132-6.

32. Yang L, Carbone DP. Tumor-host immune interactions and dendritic cell dysfunction Adv Cancer Res 2004;92:13-27.

33. Weiner HL. The mucosal milieu creates tolerogenic dendritic cells and T(R)1 and $\mathrm{T}(\mathrm{H}) 3$ regulatory cells. Nat Immunol 2001;2:671-2.

34. Tato CM, 0'Shea JJ. Immunology: what does it mean to be just 17 ? Nature 2006:441:166-8

35. Zou W. Immunosuppressive networks in the tumour environment and their therapeutic relevance. Nat Rev Cancer 2005;5:263-74.

36. Zou W. Regulatory T cells, tumour immunity and immunotherapy. Nat Rev Immunol 2006;6:295-307.

37. Michael-Robinson JM, Biemer-Huttmann A, Purdie DM, et al. Tumour infiltrating lymphocytes and apoptosis are independent features in colorectal cancer stratified according to microsatellite instability status. Gut 2001;48:360-6.

38. Quinn E, Hawkins N, Yip YL, et al. CD103+ intraepithelial lymphocytes - a unique population in microsatellite unstable sporadic colorectal cancer. Eur J Cancer 2003:39:469-75

39. Barry M, Bleackley RC. Cytotoxic T lymphocytes: all roads lead to death. Nat Rev Immunol 2002;2:401-9.

40. Phillips SM, Banerjea A, Feakins R, et al. Tumour-infiltrating lymphocytes in colorectal cancer with microsatellite instability are activated and cytotoxic. Br J Surg 2004;91:469-75.

41. Banerjea A, Ahmed S, Hands RE, et al. Colorectal cancers with microsatellite instability display mRNA expression signatures characteristic of increased immunogenicity. Mol Cancer 2004;3:21.

42. di Pietro M, Sabates BJ, Menigatti M, et al. Defective DNA mismatch repair determines a characteristic transcriptional profile in proximal colon cancers. Gastroenterology 2005:129:1047-59.

43. Kee F, Collins BJ, Patterson CC. Prognosis in familial non-polyposis colorectal cancer Gut 1991;32:513-6

44. Sankila R, Aaltonen LA, Jarvinen $\mathrm{HJ}$, et al. Better survival rates in patients with MLH1-associated hereditary colorectal cancer. Gastroenterology 1996;110:682-7.

45. Banerjea A, Bustin SA, Dorudi S. The immunogenicity of colorectal cancers with high-degree microsatellite instability. World J Surg Oncol 2005;3:26. 
46. Pages $\mathbf{F}$, Berger $\mathrm{A}$, Camus $\mathrm{M}$, et al. Effector memory $T$ cells, early metastasis, and survival in colorectal cancer. N Engl J Med 2005;353:2654-66.

47. Galon J, Costes A, Sanchez-Cabo F, et al. Type, density, and location of immune cells within human colorectal tumors predict clinical outcome. Science 2006;313:1960-4.

48. Fehervari $Z$, Sakaguchi S. Development and function of CD25+CD4+ regulatory $T$ cells. Curr Opin Immunol 2004:16:203-8.

49. Wan YY, Flavell RA. Identifying Foxp3-expressing suppressor T cells with a bicistronic reporter. Proc Natl Acad Sci USA 2005;102:5126-31.

50. Marie JC, Letterio JJ, Gavin M, et al. TGF-beta1 maintains suppressor function and Foxp3 expression in CD4+CD25+ regulatory T cells. J Exp Med 2005;201:1061-7.

51. Fontenot JD, Rasmussen JP, Williams LM, et al. Regulatory T cell lineage specification by the forkhead transcription factor foxp3. Immunity 2005;22:329-41.

52. Geissmann $\mathbf{F}$, Revy P, Regnault A, et al. TGF-beta 1 prevents the noncognate maturation of human dendritic Langerhans cells. J Immunol 1999:162:4567-75.

53. Roncarolo MG, Levings MK, Traversari C. Differentiation of T regulatory cells by immature dendritic cells. J Exp Med 2001;193:F5-9.

54. Alard P, Clark SL, Kosiewicz MM. Mechanisms of tolerance induced by TGF betatreated APC: CD4 regulatory T cells prevent the induction of the immune response possibly through a mechanism involving TGF beta. Eur J Immunol 2004;34:1021-30.
55. Liu Y, Bi X, Xu S, et al. Tumor-infiltrating dendritic cell subsets of progressive or regressive tumors induce suppressive or protective immune responses. Cancer Res 2005;65:4955-62

56. Veldhoen M, Hocking RJ, Atkins $\mathrm{CJ}$, et al. TGFbeta in the context of an inflammatory cytokine milieu supports de novo differentiation of IL-17-producing T cells. Immunity 2006;24:179-89.

57. Bettelli E, Carrier Y, Gao W, et al. Reciprocal developmental pathways for the generation of pathogenic effector TH17 and regulatory T cells. Nature 2006;441:235-8.

58. Liang SC, Tan XY, Luxenberg DP, et al. Interleukin (IL)-22 and IL-17 are coexpressed by Th17 cells and cooperatively enhance expression of antimicrobial peptides. J Exp Med 2006;203:2271-9.

59. Numasaki M, Fukushi J, Ono M, et al. Interleukin-17 promotes angiogenesis and tumor growth. Blood 2003;101:2620-7.

60. Tartour E, Fossiez F, Joyeux I, et al. Interleukin 17, a T-cell-derived cytokine, promotes tumorigenicity of human cervical tumors in nude mice. Cancer Res 1999;59:3698-704.

61. Benchetrit $\mathbf{F}$, Ciree A, Vives $V$, et al. Interleukin-17 inhibits tumor cell growth by means of a T-cell-dependent mechanism. Blood 2002:99:2114-21.

62. Dong C. Diversification of T-helper-cell lineages: finding the family root of IL-17producing cells. Nat Rev Immunol 2006;6:329-33.

\section{Editor's quiz : GI snapshot}

\section{ANSWER}

From the question on page 755

Cullen ${ }^{1}$ reported an umbilical discolouration in a patient with a ruptured extrauterine pregnancy, a sign later found to be also associated with acute pancreatitis. Grey Turner described a "dirtygreen" discolouration in the loin, also associated with acute pancreatitis. ${ }^{2}$ In acute pancreatitis, one or both signs have been reported in 3\% of all cases and have been associated with severe disease in almost $90 \%$ of these, with a total mortality rate of $39 \%$. $^{3-5}$

Computed tomography (CT) examinations may show densities around the umbilicus (multislice CT - area of Cullen sign marked; fig 1) as well as skin thickening and densities on both flanks (area of Grey Turner sign marked; fig 2).

Unfortunately, the presence of both signs in our patient was indicative of a poor prognosis. She developed pulmonary and

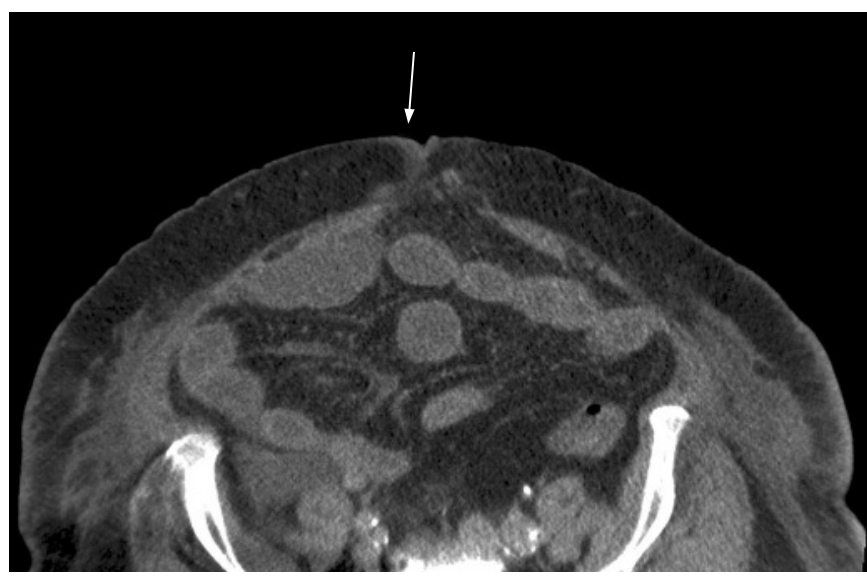

Figure 1 The ecchymosis in the periumbilical region impress as densities around the umbilicus in the area of Cullen's sign. Informed consent was obtained for publication of this figure. renal failure and finally died due to septic complications. Autopsy showed a near total necrosis of the pancreas.

Gut 2008;57:779. doi:10.1136/gut.2007.122580a

\section{REFERENCES}

1. Cullen TS. A new sign in ruptured extrauterine pregnancy. Am J Obstet Gynecol 1918;78:457.

2. Grey Turner G. Local discoloration of the abdominal wall as a sign of acute pancreatitis. Br J Surg 1920;7:394-5

3. Meyers MA, Feldberg MAM, Oliphant M. Grey Turner's sign and Cullen's sign in acute pancreatitis. Gastrointest Radiol 1989:14:31-7.

4. Bem J, Bradley III EL. Subcutaneous manifestations of severe acute pancreatitis. Pancreas 1998:16:551-5.

5. Dickson AP, Imrie CW. The incidence and prognosis of body wall ecchymosis in acute pancreatitis. Surg Gynecol Obstet 1984;159:343-7.

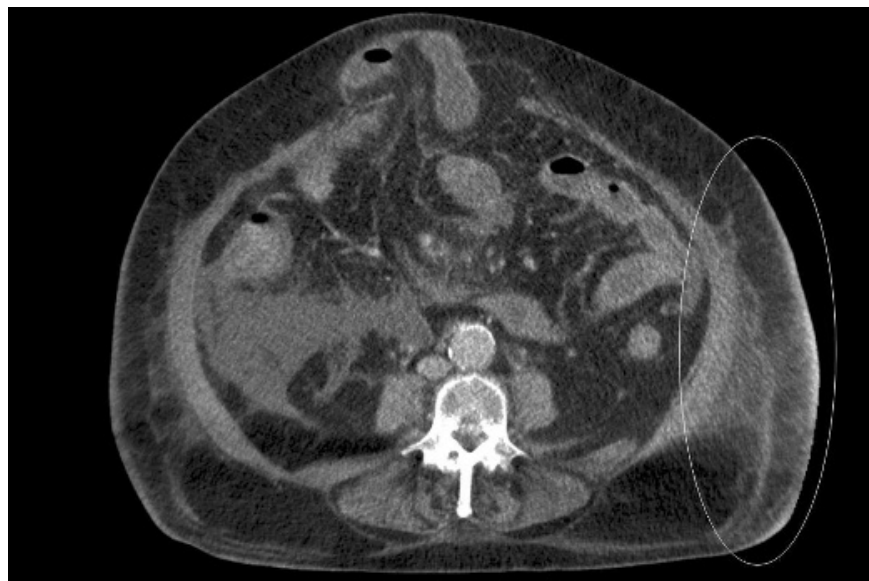

Figure 2 Skin thickening and densities on both flanks as the expression of the body ecchymosis in this area (Grey Turner's sign). Informed consent was obtained for publication of this figure. 